\title{
Influence of Water-Miscible Cutting Fluids on Tool Wear Behavior of Different Coated HSS Tools in Hobbing
}

\author{
Hironori Matsuoka ${ }^{1}$, Akio Kubo ${ }^{2}$, Hajime Ono ${ }^{3}$, Takahiro Ryu ${ }^{1}$, Hua Qiu ${ }^{2} \&$ Takashi Nakae ${ }^{1}$ \\ ${ }^{1}$ Division of Mechanical Engineering, Department of Innovative Engineering, Faculty of Science and Technology, \\ Oita University, Oita, Japan \\ ${ }^{2}$ Department of Mechanical Engineering, Faculty of Engineering, Kyushu Sangyo University, Fukuoka, Japan \\ ${ }^{3}$ Yushiro Chemical Industry Co., Ltd., Kanagawa, Japan \\ Correspondence: Hironori Matsuoka, Division of Mechanical Engineering, Department of Innovative Engineering, \\ Faculty of Science and Technology, Oita University, 700 Dannonaru Oita-shi, Oita, Japan. Tel: 81-97-554-7776. \\ E-mail: hmatsuoka@oita-u.ac.jp
}

Received: June 20, 2018

doi:10.5539/mer.v8n2p10
Accepted: September 29, 2018

Online Published: November 30, 2018

URL: https://doi.org/10.5539/mer.v8n2p10

\begin{abstract}
The present paper describes the influence of water-miscible cutting fluids on tool life (flank wear) and crater wear of various coated cutting tools and finished surface roughness, as compared with the cases of dry cutting and wet cutting using cutting oil in hobbing in an attempt to improve the working environment. Experiments were conducted by simulating hobbing by fly tool cutting on a milling machine. The following results were obtained. (1) In the case of an uncoated tool, cutting oil was more effective than dry cutting in reducing flank wear. Cutting oil and water-miscible cutting fluids were more effective in reducing flank wear than dry cutting using TiN- and TiAlN-coated tools. The use of water-miscible cutting fluids in conjunction with TiSiN- and AlCrSiN-coated tools prolongs tool life. (2) For all coated tools, the use of cutting oil or water-miscible cutting fluids were effective in reducing crater wear. Especially, water-miscible cutting fluids were effective for TiSiN- and AlCrSiN-coated tools. (3) Regarding the finished surface roughness, in the case of dry cutting, the finished surface roughness was similar for various types of coating films. When using cutting oil or a water-miscible cutting fluid, the finished surface roughness improved compared with dry cutting, independent of the type of coating film applied. The finished surface roughness obtained using water-miscible cutting fluid was approximately the same as or smaller than that obtained using cutting oil. (4) With respect to flank wear, crater wear, and finished surface roughness, the water-miscible cutting fluid of emulsion type containing a large amount of synthetic lubricating additives was suitable for the AlCrSiN-coated tool.
\end{abstract}

Keywords: cutting, gear, hobbing, coated HSS tool, water-miscible cutting fluid, tool life, crater wear, finished surface roughness

\section{Introducation}

In recent years, the use of large amounts of water-immiscible cutting oil has been scrutinized because of problems related to the working environment and global environmental pollution, e.g., because of problems such as the deterioration of the work environment due to mist and odor and the risk of ignition, even in hobbing. As an alternative, there is an increasing demand for the use of water-miscible cutting fluids as well as dry cutting and semi-dry processing (Weinert et al., 2004; Winkel 2010). The authors have been working on the development of water-miscible cutting fluids for hobbing, and the following results were obtained. (1) The water-miscible cutting fluid (emulsion type) used in the experiment prolonged the tool life, and the finished surface roughness is equivalent to that obtained by the conventional water-immiscible cutting oil for hobbing, even if the cutting speed is changed (Matsuoka et al., 2002). (2) Water-miscible cutting fluid containing a polyalkylene glycol synthetic lubricating additive was the most effective among the various emulsions (Matsuoka et al., 2006). Moreover, the results for the $\mathrm{pH}$ of the water-miscible cutting fluid indicate that the $\mathrm{pH}$ should be 8.0 in order to counter tool wear (Matsuoka et al., 2009).

With the development of coating technology, a titanium-based ceramic coating film (Sakurai \& Terao, 2007) and an aluminum-based coating film without titanium (Furuno, 2005) with improved heat resistance and wear resistance, 
are being applied to the high-speed steel (HSS) hob cutting edge in dry hobbing. However, the cutting edge temperature of the hob in dry cutting is higher than that in wet cutting, so abnormal wear of the cutting edge may occur in high-speed cutting. Therefore, we herein focus on a water-miscible cutting fluid that can be expected to have cooling and lubricating effects, and attempted to verify how water-miscible cutting fluid acts on a coated tool.

In the present study, the cutting performance of water-miscible cutting fluids for various coated tools in terms of tool wear and finished surface roughness was investigated in comparison with that of dry cutting and the use of water-immiscible cutting oil in wet cutting.

\section{Experimental Method and Conditions}

Experiments were conducted by simulating hobbing with fly tool cutting on a milling machine, as shown in Figure 1. Testing the durability of a hob by actual hobbing is complicated because the durability is influenced by several factors. After analyzing the size of chips produced by the top cutting edge of a hob tooth carrying the greatest load (Wakuri et al., 1972), a fly tool of the same shape as the single hob tooth was made for simulated hob cutting on a milling machine. The shape of the fly tool is shown in Figure 2. For the correspondence between hobbing and fly tool cutting, one of the authors recognized that the results, e.g., flank wear and finished surface roughness obtained using a fly tool with flooded water-immiscible cutting oil (katsuki \& Matsuoka, 1991) and under dry cutting conditions (Matsuoka \& Tsuda, 2000), generally agree with those obtained by hobbing. Moreover, the effectiveness and efficiency of the fly tool cutting test was recognized by investigating the tool wear characteristics for high-speed dry hobbing through a fly tool cutting experiment (Rech, 2006). Therefore, the experimental results for fly tool cutting appear to be applicable to hobbing on a hobbing machine.

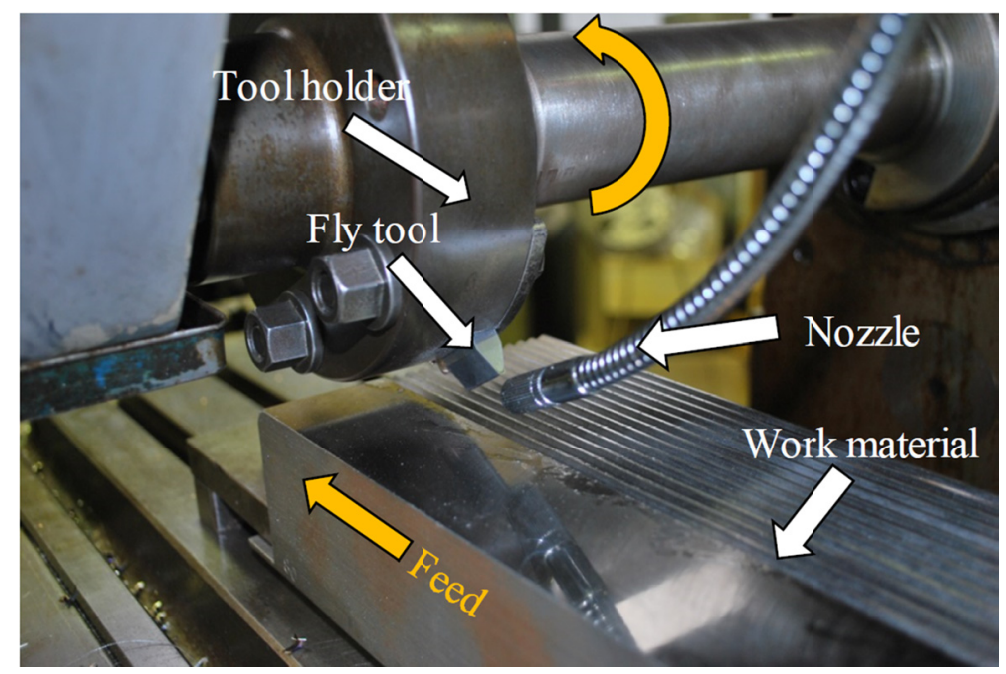

Figure 1. Experimental setup of the fly tool, work material, and oil

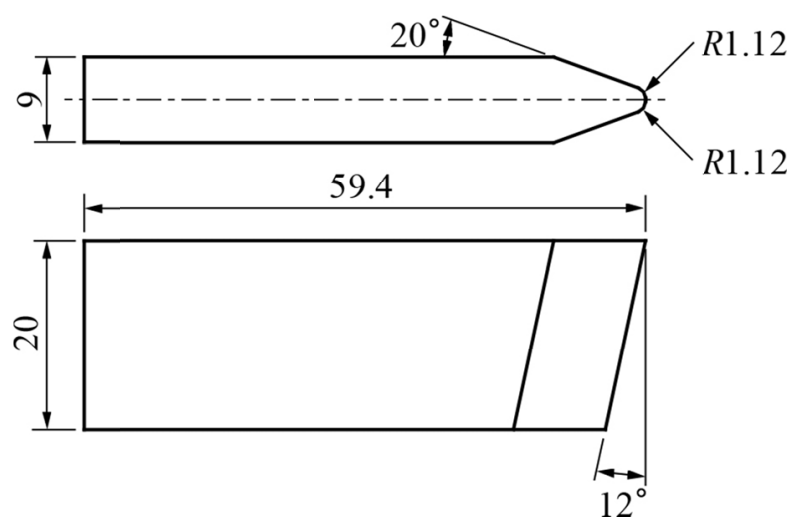

Figure 2. Profile of the fly tool 
The dimensions of the gear and the hob used in the experiments are listed in Table 1. The experimental conditions for the milling machine are listed in Table 2. Here, the maximum chip produced by the No.3 tooth of a hob was simulated.

Fly tool cutting was performed by upcut milling. Here, in Figure 3, when the turning radius of the cutting edge is $\mathrm{r}$, the chip length $L$ is expressed by the equation $L=r \theta$, so the cutting depth $h$ in the milling machine is expressed by $h$ $=r(1-\cos \theta)$, and the table feed $f^{\prime}$ is expressed by $f^{\prime}=S / \sin \theta . S$ is the chip thickness. The fly tool used in these tests is formed from HSS JIS SKH55 (Quenching temperature: $1200^{\circ} \mathrm{C}$, Tempering temperature: $550^{\circ} \mathrm{C} \times 3$ times, Vickers hardness: HV862, Transverse rupture strength: $3612 \mathrm{~N} / \mathrm{mm} 2$ ).

Table 1. Dimensions of the gear and hob

\begin{tabular}{|c|c|c|c|}
\hline \multicolumn{2}{|c|}{ Gear } & \multicolumn{2}{|c|}{ Hob } \\
\hline Module & 3 & Module & 3 \\
\hline Pressure angle & \multirow{2}{*}{$20^{\circ}$} & Pressure angle & $20^{\circ}$ \\
\hline \multirow{2}{*}{ Number of teeth } & & Lead angle & $35^{\prime} 18^{\prime \prime}$ \\
\hline & 42 & \multirow{2}{*}{ Form } & \multirow{2}{*}{$\begin{array}{l}\text { 3-thread, } \\
\text { Right hard }\end{array}$} \\
\hline Helix angle & $0^{\circ}$ & & \\
\hline Pitch diameter & $126 \mathrm{~mm}$ & Size & $25 \times \phi 40$ \\
\hline \multirow{2}{*}{ Face width } & \multirow{2}{*}{$40 \mathrm{~mm}$} & Rake angle & $0^{\circ}$ \\
\hline & & Relief angle & $12^{\circ}$ \\
\hline Cutting depth & $6.75 \mathrm{~mm}$ & Number of gashes & 12 \\
\hline Tooth profile & lepth tooth & Gash & Straight \\
\hline
\end{tabular}

Table 2. Experimental conditions for hobbing by fly tool cutting on a milling machine

\begin{tabular}{|c|c|c|c|c|c|c|c|}
\hline \multicolumn{4}{|c|}{ Hobbing } & \multirow{2}{*}{\multicolumn{4}{|c|}{ Fly tool cutting on milling machine }} \\
\hline \multicolumn{2}{|c|}{ Condition } & \multicolumn{2}{|c|}{ Size of maximum chip } & & & & \\
\hline \multirow{2}{*}{$\begin{array}{l}\text { Number of } \\
\text { thread }\end{array}$} & \multirow{2}{*}{$\begin{array}{l}\text { Feed of } \\
\text { hob } \\
\mathrm{mm} / \mathrm{rev}\end{array}$} & \multirow{2}{*}{$\begin{array}{l}\text { Length } \\
\mathrm{mm}\end{array}$} & \multirow{2}{*}{$\begin{array}{c}\text { Thickness } \\
\text { mm }\end{array}$} & \multirow{2}{*}{$\begin{array}{l}\text { Feed of } \\
\text { table } \\
\mathrm{mm} / \mathrm{rev}\end{array}$} & \multirow{2}{*}{$\begin{array}{l}\text { Depth of } \\
\text { cut } \\
\quad \mathrm{mm}\end{array}$} & \multicolumn{2}{|c|}{$\begin{array}{l}\text { The corresponding cutting } \\
\text { data to hobbing a gear }\end{array}$} \\
\hline & & & & & & $\begin{array}{l}\text { Revolution } \\
\text { of fly tool }\end{array}$ & $\begin{array}{l}\text { Length of } \\
\text { groove to } \\
\text { be cut m }\end{array}$ \\
\hline 3 & 3 & 23.57 & 0.27 & 0.99 & 3.25 & 315 & 0.31 \\
\hline
\end{tabular}

Note: The turning radius of the tip of fly tool is $85 \mathrm{~mm}$.

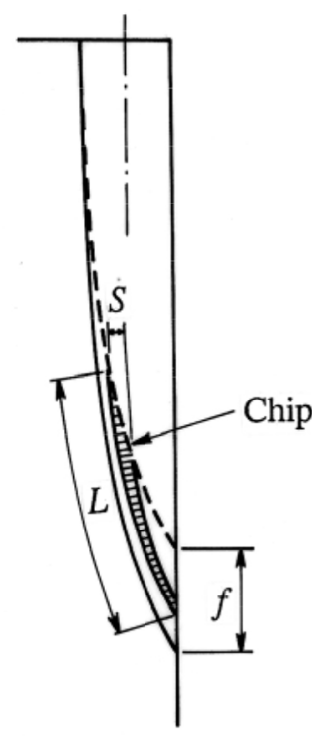

(a) Hobbing

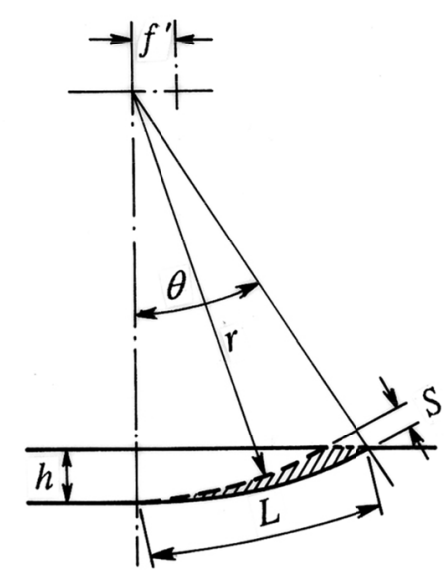

(b) Fly tool cutting

Figure 3. Cutting relationship in hobbing and fly tool cutting 
The tests were performed with a fly tool without coating (abbreviated as uncoated tool) and with fly tools coated with TiN, TiAlN, TiSiN, and AlCrSiN films (abbreviated as TiN-, TiAlN-, TiSiN- and AlCrSiN-coated tools). The thickness of each of the coating films was approximately $2 \mu \mathrm{m}$. In the presentstudy, cutting tests were conducted using fly tools without a coating on the rake face, because, in many cases, the rake faces of hobs are not coated due to regrinding in the workshop. The coating film on the rake face was removed by grinding. Figure 4 shows the types of wear at the tip of the tool. The widths of the center wear, the top corner part wear on the top cutting edge, and the corner wear occurring at the boundary region between the rounded portion on the top cutting edge and the side cutting edge, as well as the depth of crater wear, were measured. In this experiment, a width of maximum flank wear of $0.3 \mathrm{~mm}$ (maximum of the center wear, the top corner part wear, and the corner wear) was evaluated as the tool life criterion. The finished surface roughness Rz on the side region of the cutting groove in the cutting direction corresponding to the gear tooth surface was measured.

The work material used in the tests was JIS SCM 415 chrome molybdenum steel, which have been used as gear materials for automobiles, and the sample was $500 \mathrm{~mm}$ in length, $100 \mathrm{~mm}$ in width, and $100 \mathrm{~mm}$ in thickness. The chemical compositions are given in Table 3 . The cutting speed of $117 \mathrm{~m} / \mathrm{min}$ was selected practically. The milling machine used in the tests was a $2 \mathrm{MF}$ model (universal type) manufactured by Hitachi Seiki Co., Ltd. The experiments were carried out using water-immiscible cutting oil (Oil A, also referred to as cutting oil), which is generally used for hobbing. The properties and components of Oil A are shown in Table 4. As water-miscible cutting fluids, an emulsion (Fluid B), a solute (Fluid C), and a solution (Fluid D) were used and diluted 30 times with tap water. Their properties and components are shown in Table 5. The cutting fluid was supplied at a sufficient rate of $2.4 \mathrm{~L} / \mathrm{min}$ (supplied pressure: $0.5 \mathrm{MPa}$ ) from the rake face side.

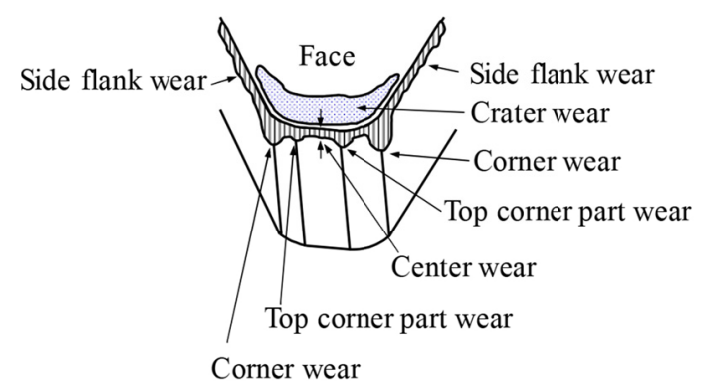

(a) Wear at the cutting edge

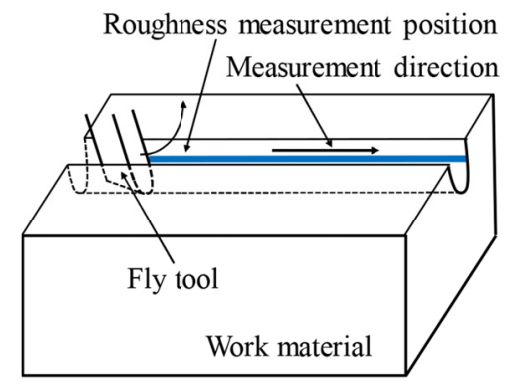

(b) Roughness measurement position

Figure 4. Wear at the cutting edge and finished surface roughness measurement position

Table 3. Compositions and hardness of work material

\begin{tabular}{|c|c|c|c|c|c|c|c|c|c|c|}
\hline \multirow{2}{*}{ Kind } & \multicolumn{9}{|c|}{ Composition } & \multirow{2}{*}{$\begin{array}{c}\text { Brinell } \\
\text { hardness } \\
\text { HB }\end{array}$} \\
\hline & $\mathrm{C}$ & $\mathrm{Si}$ & $\mathrm{Mn}$ & $\mathrm{P}$ & S & $\mathrm{Cu}$ & $\mathrm{Ni}$ & $\mathrm{Cr}$ & $\mathrm{Mc}$ & \\
\hline SCM 415 & 0.15 & 0.19 & 0.71 & 0.015 & 0.015 & 0.01 & 0.02 & 0.98 & 0.18 & 143 \\
\hline
\end{tabular}

Table 4. Cutting oil used in the test

\begin{tabular}{c|c}
\hline Item & Oil A \\
\hline Appearance & $\begin{array}{c}\text { Brown } \\
\text { transparency }\end{array}$ \\
\hline $\begin{array}{c}\text { Specific gravity } \\
\left(15^{\circ} \mathrm{C}, \mathrm{g} / \mathrm{cm}^{3}\right)\end{array}$ & 0.89 \\
\hline $\begin{array}{c}\text { Kinematic viscosity } \\
\left(40^{\circ} \mathrm{C}, \mathrm{mm}^{2} / \mathrm{s}\right)\end{array}$ & 28 \\
\hline Flash point $\left(\mathrm{COC},{ }^{\circ} \mathrm{C}\right)$ & 210 \\
\hline $\begin{array}{c}\text { Copper plate corrosion } \\
\left(100^{\circ} \mathrm{C}, 1 \mathrm{~h}\right)\end{array}$ & Inactive $(1)$ \\
\hline Fatty oil & $0 \sim 10 \%$ \\
\hline Sulfuric EP additive & $10 \sim 30 \%$ \\
\hline
\end{tabular}


Table 5. Water-miscible cutting fluids used in the test

\begin{tabular}{c|c|c|c|c}
\hline \multicolumn{2}{c|}{ Item } & \multicolumn{1}{c|}{ Fluid B } & \multicolumn{1}{c|}{ Fluid C } & Fluid D \\
\hline \multirow{2}{*}{ Appearance } & Original & $\begin{array}{l}\text { Light yellow } \\
\text { liquid }\end{array}$ & $\begin{array}{l}\text { Light yellow } \\
\text { liquid }\end{array}$ & $\begin{array}{l}\text { Light blue } \\
\text { liquid }\end{array}$ \\
\cline { 2 - 5 } & $\times 30$ & $\begin{array}{l}\text { Light yellow } \\
\text { emulsion }\end{array}$ & $\begin{array}{l}\text { Light blue } \\
\text { translucency }\end{array}$ & Transparency \\
\hline Specific gravity $\left(15^{\circ} \mathrm{C}, \mathrm{g} / \mathrm{cm}^{3}\right)$ & Original & 0.94 & 0.99 & 1.04 \\
\hline $\mathrm{pH}$ & $\times 30$ & 9.9 & 9.9 & 10.2 \\
\hline Surface tension $(\mathrm{mN} / \mathrm{m})$ & $\times 30$ & 34 & 33 & 49 \\
\hline Mineral oil & Original & - & - & - \\
\hline Synthetic lubricating additive & Original & $30 \%<$ & $10 \sim 30 \%$ & - \\
\hline Sulfuric EP additive & Original & - & - & - \\
\hline Surface active agent & Original & $0 \sim 10 \%$ & $30 \%<$ & $30 \%<$ \\
\hline
\end{tabular}

\section{Experimental Results and Discussions}

\subsection{Tool Life and Tool Wear Behavior}

In order to confirm the reproducibility of flank wear and crater wear in the present study, tests were conducted under several conditions, and two tests were conducted for each condition. In these tests, the width of flank wear and the depth of crater wear were considered to be approximately the same.

Figure 5 shows the life of tools with various coatings. The tool life criterion is a width of maximum flank wear of $0.3 \mathrm{~mm}$. In the case of an uncoated tool, the tool life is short. However, using cutting oil (Oil A), the tool life is reached at a cutting groove length of $1.5 \mathrm{~m}$ (corresponding to approximately five gears). The tool lives obtained using three types of water-miscible cutting fluids are equivalent to or slightly shorter than that obtained using Oil A. In the case of the TiN-coated tool, using Oil A, the tool life is reached at a cutting groove length of $18.9 \mathrm{~m}(60$ gears). The tool lives using three water-miscible cutting fluids are shorter than that using Oil A, and the tool life increases in the order of Fluid B, Fluid C, and Fluid D. In the case of the TiAlN-coated tool, using Oil A, the tool life is reached at a cutting groovelength of $6.9 \mathrm{~m}$ (22 gears), but the tool lives using the three water-miscible cutting fluids are shorter than that using Oil A. In the case of the TiSiN-coated tool, using Oil A, the tool life is reached at a cutting groove length of $9.9 \mathrm{~m}$ ( 32 gears). The tool lives obtained using the three water-miscible cutting fluids were longer than that using Oil A, and, when using Fluid B, the tool life is reached at a cutting groove length of $16 \mathrm{~m}(52$ gears), which is longest among the water-miscible cutting fluids. The tool life for Fluid $\mathrm{C}$ was higher than that for Fluid D. In the case of the AlCrSiN-coated tool, using Oil A, the tool life is reached at a cutting groove length of $16.5 \mathrm{~m}$ (53 gears). The tool lives obtained using the three water-miscible cutting fluids were longer than that obtained using Oil A, and, when using Fluid B, the tool life is reached at a cutting groove length of $32.7 \mathrm{~m}$ (105 gears), which was the longest among the water-miscible cutting fluids. The tool life for Fluid $\mathrm{C}$ was longer than that for Fluid D.

The above results revealed that there is a high possibility that the cutting fluid penetrates into the cutting point and it is thought that the fluid is also present around the contact interface between the tool and the workpiece (Shinozaki \& Yoshikawa, 1958; Ohgo et al., 1976; Usui \& Mizuhara, 1980), so the effects of water-miscible cutting fluids may differ depending on the type of coating. In the case of an untreated tool, cutting oil and water-miscible cutting fluid are effective. Since Oil A contains a fatty oil and a sulfuric extreme pressure additive, a cutting fluid having excellent lubricating performance appears to be suitable for TiN- and TiAlN-coated tools. Moreover, in the case of the TiN-coated tool, the tool life increases in the order of emulsion type, soluble type, and solution type. The reason for this is considered to be that the cooling performance, rather than the lubricating performance among the water-miscible cutting fluids tested, is more improved, because, although a large amount of synthetic lubricating additives is contained in the emulsion, synthetic lubricating additives are not included in the solution. In the case of the TiAlN-coated tool, even if the type of water-miscible cutting fluid is changed, the tool life will not change. Since the lubricating effect of the synthetic lubricating additives in the emulsion and the cooling effect of the solution by water are considered, the tool lives obtained with both fluids are the same, but the slightly longer tool life obtained using the solute is thought to be due to both the lubricating and cooling effects. For TiSiN- and AlCrSiN-coated tools, since the tool life increased in the order of the solution, the soluble and the emulsion, the emulsion (Fluid B), which contains a large amount of synthetic lubricating additives, was effective because of its excellent lubrication performance rather than its cooling performance. These reasons will be discussed below. 
Table 6 shows the Vickers hardness and oxidation temperature of various coating films. In the case of dry cutting, as shown in Figure 5, the tool life tends to increase as the hardness and oxidation temperature of the various coating films increase, and the tool wear appears to be related to the hardness and the oxidation temperature of the coating films. When using cutting oil (Oil A), the tool life increases compared to that for dry cutting for all of the coated tools considered herein, and the tool life tends to increase in coated tools with relatively low hardness. In particular, in the low-hardness TiN-coated tool, the tool life is the longest, which appears to be due to the lubricating effect of Oil A. When using the three water-miscible cutting fluids, the tool life increases compared with dry cutting for all of the coated tools considered herein. In particular, the tool life increases in the TiSiN- and AlCrSiN-coated tools, and it is inferred that in addition to the relatively high oxidation temperature of these coated tools, the cooling effect of the water-miscible cutting fluid is related to the reduction in the cutting temperature. Moreover, when comparing the TiN- and the TiAlN-coated tools, although the TiAlN-coated tool has high hardness and high oxidation temperature, the reason for the short tool life for both cutting oil and water-miscible cutting oil is the occurrence of delamination of the coating film surface layer at the beginning of cutting (see Figure 6).

Among the coated tools used in the experiments, the cutting performance of the AlCrSiN-coated tool is particularly excellent, so we hereinafter consider the flank wear behaviour of the AlCrSiN-coated tool.

Although the cutting temperature was not measured in these experiments, in order to examine the cooling performance, the cutting temperature was estimated based on the color difference of the chip that was formed. Figure 7 shows the color of the chip at the beginning of cutting (cutting groove length: $0.5 \mathrm{~m}$ ) using the $\mathrm{AlCrSiN}$-coated tool and the three water-miscible cutting fluids. In the case of dry cutting, the color from a portion of the beginning of the cut of a chip to a portion of the end of the cut is dark blue-purple. However, in the case of Oil A, the color from the beginning of the cut to the end of the cut of a chip is dark brown. When water-miscible cutting fluids are used, the chip turns brown to pale brown in the order of Fluid B, Fluid C, and Fluid D. Based on the chip color, the cutting temperature decreases in the order of dry cutting, Oil A, Fluid Fluid C, and Fluid D. Figure 8 shows the color of the chip after cutting groove of $15 \mathrm{~m}$. The order of the chip color is the same as in the case of the beginning of cutting. Fujimura reported that the chip color is the interference color of the oxide film formed on the chip surface in an extremely short time, which is rapidly heated by the cutting heat and is quenched by the atmosphere. These interference colors are indicators of the cutting temperature, under the same cutting atmosphere (Fujimura, 1991). In this experiment, however, although the atmosphere differs in dry cutting and wet cutting, there is a high possibility that the chip color differs as a result of cooling by the cutting fluid. It is thought that the temperature at the tool edge during cutting depending on the presence or absence of cutting fluid does not change so much, but when the fluid exists at the cutting region, the cutting edge temperature is instantaneously lowered and the chip itself is also cooled, so it is presumed that the difference in chip color has appeared because of the difference in temperature.

In the case of the $\mathrm{AlCrSiN}$-coated tool, the longer tool life obtained using water-miscible cutting fluid (as compared with the cutting oil) is considered to be due to both the lubricating and cooling effects of the water-miscible cutting fluid. Moreover, although the cutting temperature when using the emulsion (Fluid B) is higher than when using other water-miscible cutting fluids, the longer tool life obtained using Fluid B is considered to be due to the excellent thermal and oxidative stability of synthetic lubricating additives and because of the high affinity to the metal surface and high lubricity at high temperature.

Figure 9 shows the progress curves for the maximum wear width obtained using various cutting fluids when using the $\mathrm{AlCrSiN}$-coated tool. In the case of dry cutting, the wear dramatically increases until reaching a cutting groove length of $2.5 \mathrm{~m}$, and the average wear rate (increment of maximum wearwidth per $1 \mathrm{~m}$ of cutting groove length) was $0.127 \mathrm{~mm} / \mathrm{m}$. In the case of Oil A, initial wear was not observed, and the wear increased substantially and linearly from the beginning of cutting. The average wear rate was $0.019 \mathrm{~mm} / \mathrm{m}$. For three types of water-miscible cutting fluids, initial wear was not observed and the wear increased approximately linearly from the beginning of cutting. The average wear rates were $0.014 \mathrm{~mm} / \mathrm{m}, 0.012 \mathrm{~mm} / \mathrm{m}$, and $0.009 \mathrm{~mm} / \mathrm{m}$ for Fluid D, Fluid C, and Fluid B, respectively. 


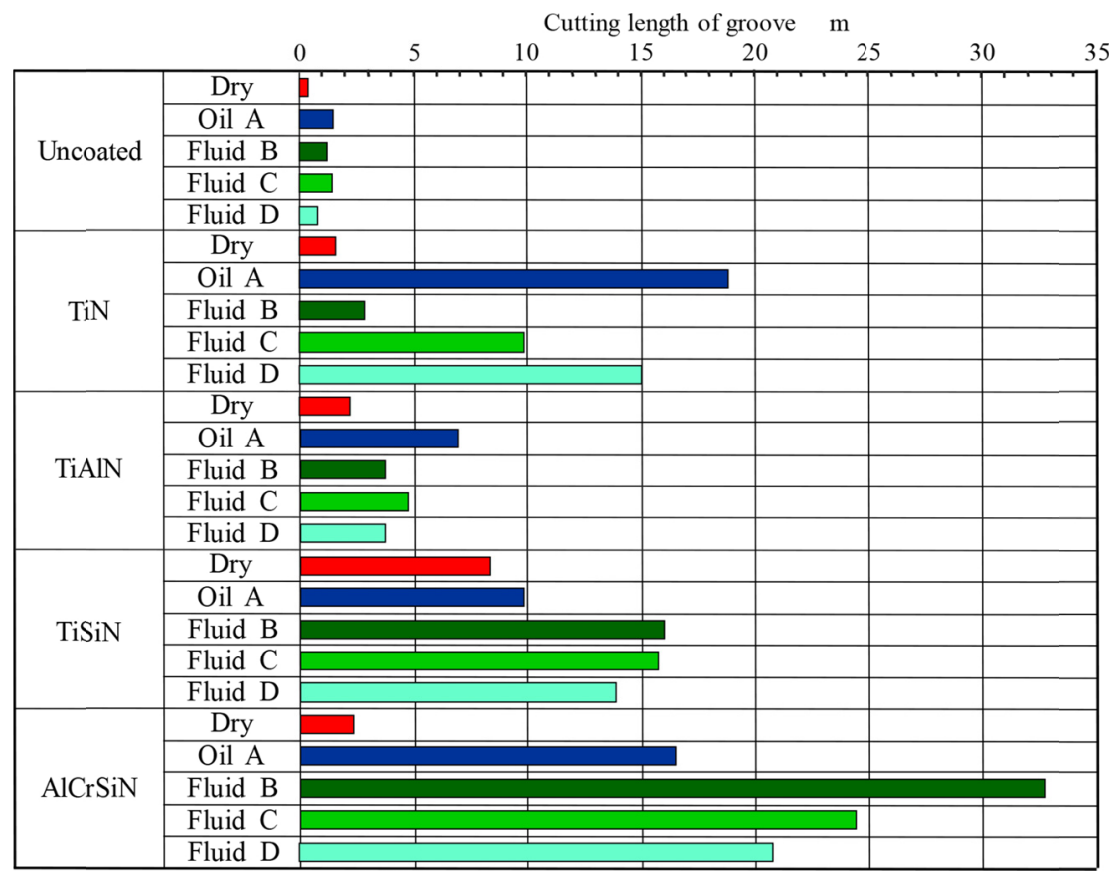

Figure 5. Tool life for various coated tools and water-miscible cutting fluids

Table 6. Characteristics of the coating film

\begin{tabular}{c|c|c|c}
\hline Coating film & $\begin{array}{c}\text { Vickers hardness } \\
\text { HV }\end{array}$ & $\begin{array}{c}\text { Oxidation temperature } \\
{ }^{\circ} \mathrm{C}\end{array}$ & Coefficient of friction \\
\hline TiN & 2300 & 600 & 0.40 \\
\hline TiAlN & 3200 & 1000 & 0.30 \\
\hline TiSiN & 3700 & 1300 & 0.43 \\
\hline AlCrSiN & 3000 & 1100 & 0.55 \\
\hline
\end{tabular}

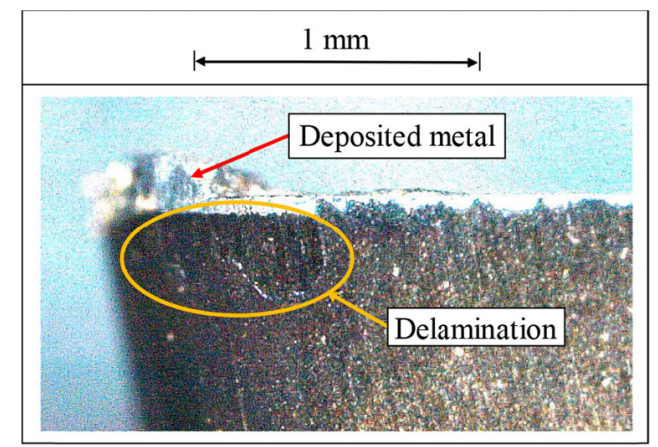

Figure 6. Delamination for the coating film on the TiAlN-coated tool (Fluid B, cutting groove length: $0.5 \mathrm{~m}$ )

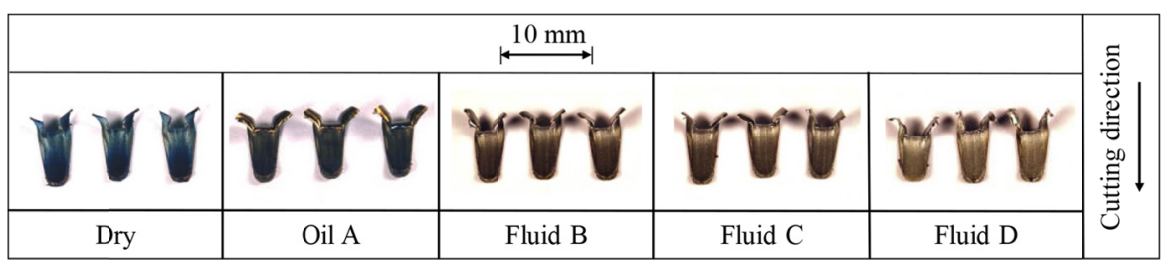

Figure 7. Color of chips obtained using the $\mathrm{AlCrSiN}$-coated tool ( cutting groove length: $0.5 \mathrm{~m}$ ) 


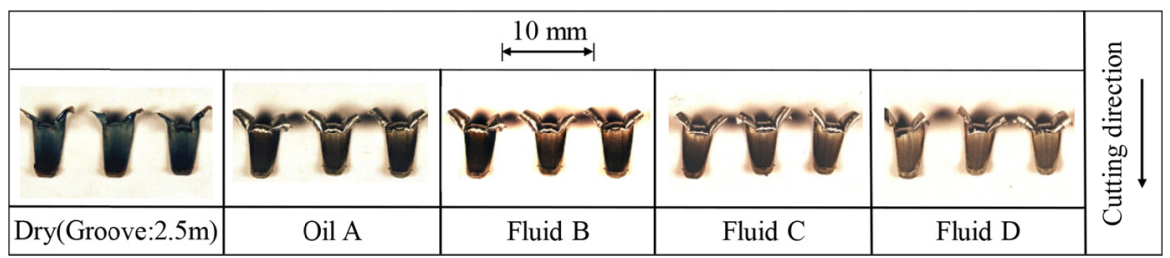

Figure 8. Color of chips obtained using the AlCrSiN-coated tool (cutting groove length: $15 \mathrm{~m}$ )

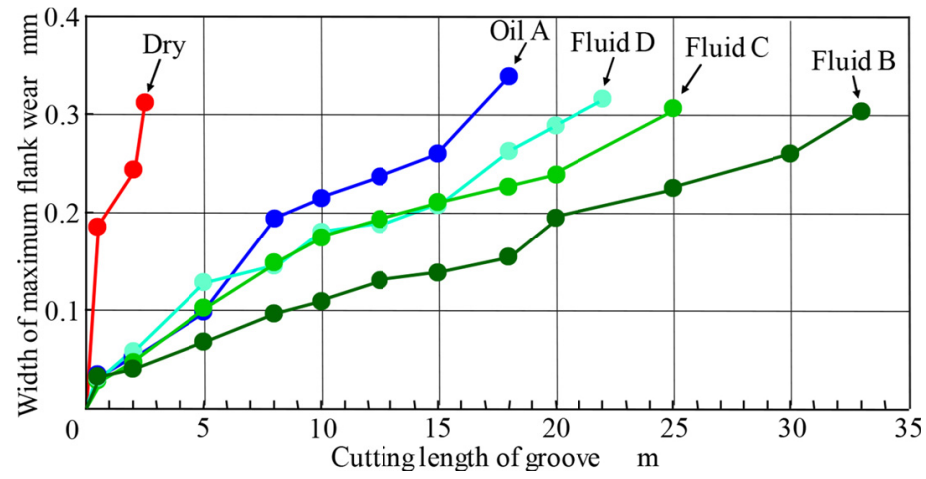

Figure 9. Progress curves of maximum flank wear obtained using various cutting fluids (AlCrSiN-coated tool)

Figure 10 shows the width of flank wear when using various cutting fluids and an $\mathrm{AlCrSiN}$-coated tool. In the case of dry cutting, the center wear is large and deposited metal is observed on the top cutting edge. The reason for this behavior is assumed to be the influence of thermal load, because the chip cut at the position of the center of the top cutting edge is thick (Terashima \& Ueno, 1977), which heavily loads the cutting edge. Moreover, a significant lubricating effect cannot be expected and deposited metal is generated at the cutting edge. Thus, the center wear is considered to be dominated by welding wear (Nakayama, 1978), which is caused a lack of lubrication, or transfer-type wear (Takeyama, 1982a), caused by the substrate due to tearing of the deposited metal from the cutting edge. The center wear is smaller using Oil A than for dry cutting, and wears occurs at the two top corners. When using cutting oil, center wear appears to decrease because of the high lubricating performance. In contrast, in the case of the three water-miscible cutting fluids, for Fluid B and Fluid C, mechanical abrasion (Takeyama, 1982b) was observed in which the cutting edge was scraped off, but for Fluid D, the cutting edge remained intact. When using the three water-miscible cutting fluids, a regular wear pattern that is parallel to the cutting edge is observed. When using water-miscible cutting fluids, the center and top corner wear appear to be reduced by the cooling effect, as compared to dry cutting and wet cutting using the cutting oil. The tool wear patterns, which appear to be abrasive wear patterns, obtained using the cutting oil and water-miscible cutting fluids considered herein are similar.

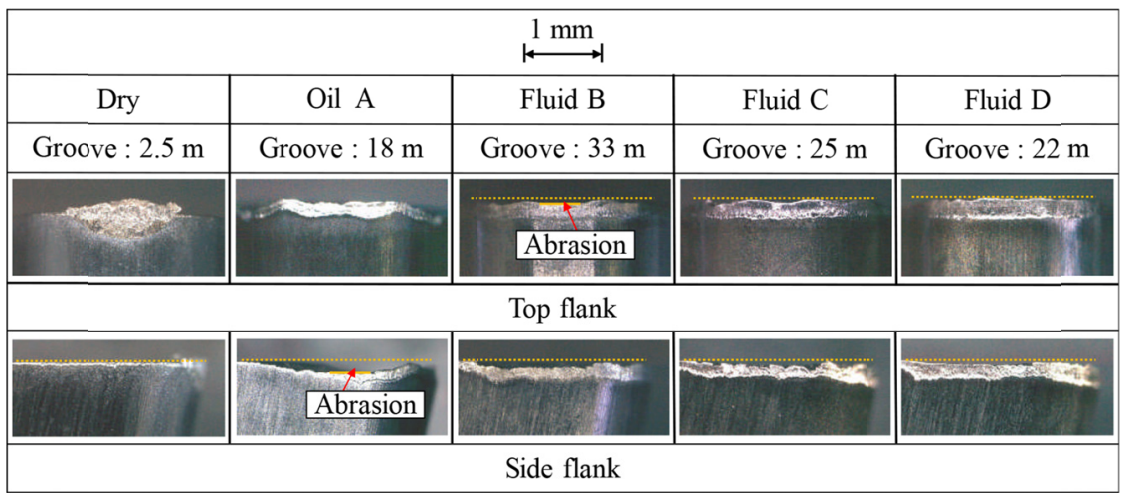

Figure 10. Flank wear obtained using various cutting fluids (AlCrSiN-coated tool)

In the case of dry cutting, at side cutting edges, the amount of wear is small because the length of the cutting groove is as short as $2.5 \mathrm{~m}$ and the cutting edge remains intact, and regular wear parallel to the side cutting edge is also 
observed. In the case of Oil A, the side flank wear increases because the cutting edge including the rake face is largely scraped away, and the actual wear area is small. The wear pattern is considered to indicate corrosion wear. Because EP additives may promote wear due to the chemical reaction of the additive and the metal (Okabe, 1973; Kimura \& Okabe, 1985; Hida, 1985). On the other hand, in the case of three water-miscible cutting fluids, the mechanical abrasion is the largest for Fluid B, followed by Fluid B and Fluid C in that order, and the cutting edge remains intact for Fluid D. The wear patterns generated when using the water-miscible cutting fluids appear to be due to abrasive wear parallel to the cutting edge, but chipping is also observed at the cutting edge.

\subsection{Crater Wear Behavior}

Figure 11 shows the influence of the cutting fluids on the depth of crater wear for various coated tools. The depth of crater wear for $1 \mathrm{~m}$, which is obtained by dividing the crater depth by the cutting groove length, is evaluated, because the length of the cutting groove until the tool life is reached differs according to the coated tool. In the case of the uncoated tool, the depth of crater wear decreased in the order of Fluid B, Fluid C, and Fluid D, and the crater depth for Fluid D was approximately the same as for Oil A. In dry cutting, the depth of crater wear could not be measured because the deposited metal adhered to the rake face. In the case of the TiN-coated tool, the crater wear is considerably small when using water-miscible cutting fluids, as compared with both dry cutting and wet cutting using Oil A. In addition, the crater wear decreases in the order of Fluid B, Fluid C, and Fluid D. In the case of the TiAlN-coated tool, the crater wear is considerably small when using water-miscible cutting fluids, as compared to dry cutting, and is equivalent or small than when using Oil A. The crater wear increases in the order of Fluid B, Fluid C, and Fluid D. In the case of the TiSiN- and AlCrSiN-coated tools, the crater wear increases in the order of Fluid B, Fluid C, and Fluid D, but the difference in the crater wear depth is small. The crater wear is small when using the water-miscible cutting fluids, as compared to dry cutting and wet cutting using Oil A. Among the various coated tools, the crater wear is smallest when water-miscible cutting fluids are used in conjunction with the AlCrSiN-coated tool.

Figure 12 shows the conditions of the rake face and the crater wear profiles at the end of cutting obtained through dry cutting and wet cutting using Oil A and Fluid B when used in conjunction with the AlCrSiN-coated tool. The crater wear profiles were measured at the center of the tool. In all cases of dry cutting and wet cutting using Oil A and Fluid B, metal was deposited on the crater wear region. In particular, in the case of dry cutting, the deposited metal adheres to the entire crater wear region. Under these experimental conditions, when most coated tools and cutting fluids are used, the actual depth of crater wear cannot be measured due to the adhesion of deposited metal. The measurement results shown in Figure 12 indicate the apparent crater wear depth. In particular, when the water-miscible cutting fluids are used, the crater wear is assumed to be small because the rake face was covered with the deposited metal. Based on the condition of the rake face, the contact length with the chip at the center of the rake face (hereinafter abbreviated as contact length) obtained using Fluid B is shorter than that obtained using Oil A, despite the long cutting groove length obtained using Fluid B.

Figure 13 shows the contact lengths with chips at the end of cutting at the center of the rake face for various coated tools using the cutting fluid. In the case of the uncoated tool, the contact length is approximately the same for dry cutting and wet cutting using Oil A, Fluid B, Fluid C, and Fluid D. For various coated tools, the contact length is shorter when using the water-miscible cutting fluids as compared to dry cutting and wet cutting using Oil A, although the cutting groove lengths are different. Among the water-miscible cutting fluids, the contact length obtained using Fluid B is the shortest. The shorter the contact length is, the better the cutting condition will be. This suggests that the cutting forces decrease and that the friction condition on the rake face affects the plastic area in the chip, which affects the shear angle, i.e., the cutting forces change (Takeyama, 1982c).

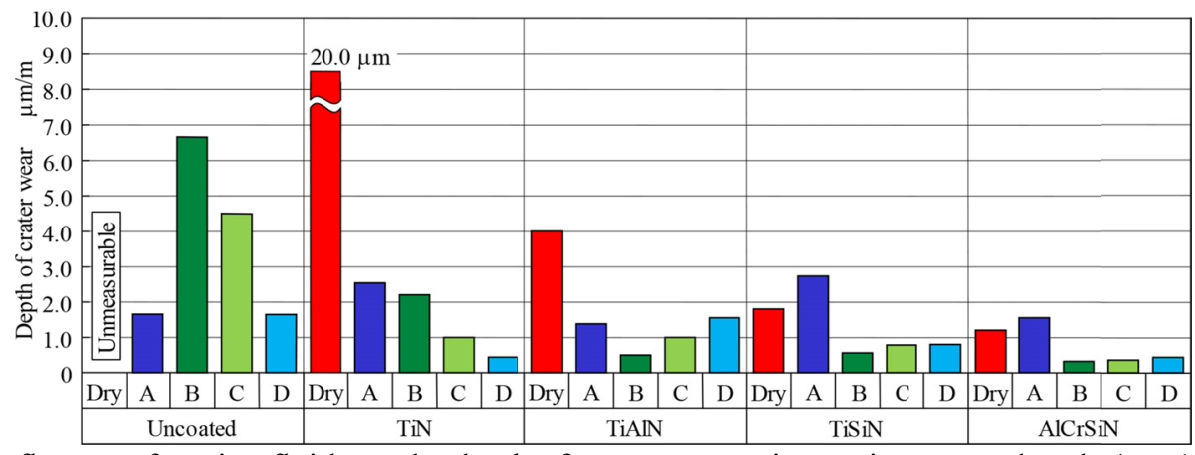

Figure 11. Influence of cutting fluids on the depth of crater wear using various coated tools (per $1 \mathrm{~m}$ of cutting groove length) 


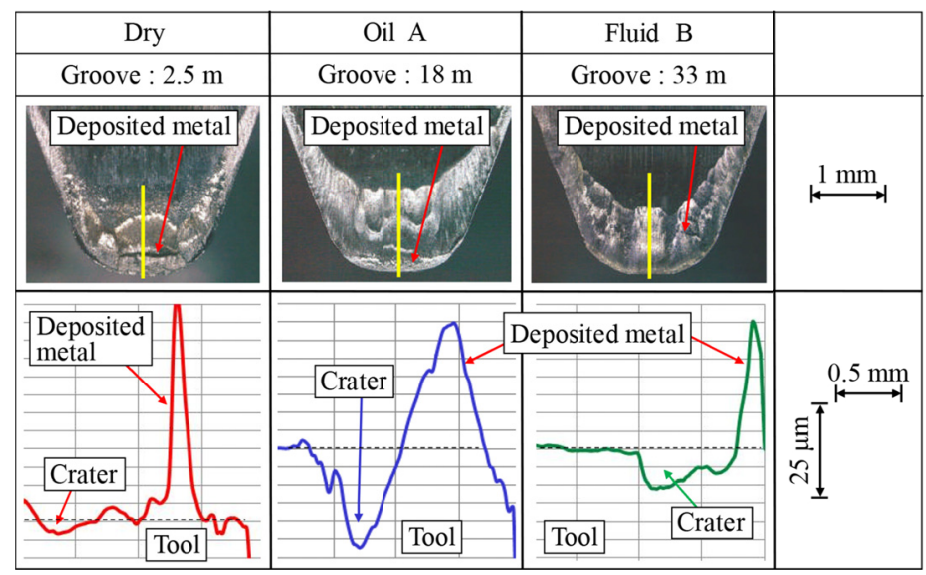

Figure 12. Conditions of the rake face and crater wear profiles obtained using the $\mathrm{AlCrSiN}$-coated tool (dry cutting and wet cutting using Oil A and Fluid B)

Therefore, when using Fluid $\mathrm{B}$, the friction condition on the rake face is estimated to be improved due to the lubricating effect of the synthetic lubricating additive and the decrease in the cutting forces, where the shear angle becomes large and the contact length may be the shortest. The contact length for Fluid $\mathrm{C}$ appears to be longer than that for Fluid B because the content of synthetic lubricant additives in Fluid C is smaller than that in Fluid B. The contact length is longest for Fluid D, followed by Fluid B and Fluid C, in that order, even though Fluid D does not contain lubricating components. Based on this consideration, the cooling and lubricating effects influence the friction condition of the chip on the rake face when the water-miscible cutting fluids are used. However, in the case of cutting oil (Oil A), which has an excellent lubricating performance, the contact length is longer than that for water-miscible cutting fluids. Sulfuric extreme pressure additives are added to Oil A, which react with the cutting tool and the newly generated surfaces of chips, in which an iron sulfide coating is formed. In addition, fatty oil is added, and its adsorption film is formed on the friction surface, which reduces crater wear. In this experiment, however, the crater wear obtained using Oil A was larger and the contact length was longer than those obtained using water-miscible cutting fluids. For this reason, chemical reactions with metals are involved in corrosion wear (Okabe, 1973; Kimura \& Okabe, 1985). Corrosive wear is assumed to have occurred because the cutting phenomenon is also a tribological phenomenon.

On the other hand, the cutting temperature is assumed to vary depending on the lubricating and cooling effects in dry cutting and with various cutting fluids, i.e., the deposited metal on the rake face appears to be different. In this experiment, as shown in Figure 12, the crater wear was covered with the deposited metal.

In addition, the influence of the coating film applied to the flank face on the rake face is thought to be small because the experiment is performed using tools without a coating film on the rake face. At the beginning of cutting, contact between the coating film on the flank face and the work material may be considered, in which the flank wear does not occur because a coating film having a thickness of approximately $2 \mu \mathrm{m}$ is applied to the flank face side. As the cutting continues, the coating film wears out or becomes damaged, and the substrate appears. However, the coating film still remains on the flank face, and the substrate and the coating film come into contact with the work material (see Figure 14). In other words, it is expected that the cutting forces and the cutting temperature will differ with the friction coefficient of the coating film (see Table 6) applied to the flank face, which is thought to affect the crater wear depth and wear characteristics of the rake face. Moreover, when flank wear occurs, the cutting temperature may increase, which may be due to the difference in metal deposition on the rake face.

In this experiment, when the water-miscible cutting fluids are used, the cutting temperature is assumed to decrease, as compared with the cutting oil, due to the cooling effect, as shown in Figures 7 and 13. Therefore, a large amount of deposited metal appears to have been generated on the rake face from the beginning of cutting. When using water-miscible cutting fluids, the crater wear is small because the deposited metal covers the rake face, the protective effect is notable, and the contact length is short.

Based on the above-mentioned considerations, the crater wear on the rake face is considered to be related to the mechanism of the cutting fluid and the occurrence of metal deposition, which is considered to be affected by the difference in cutting forces and cutting temperature due to the difference in the coating film on the flank face. From now on, it is necessary to measure the cutting forces. 

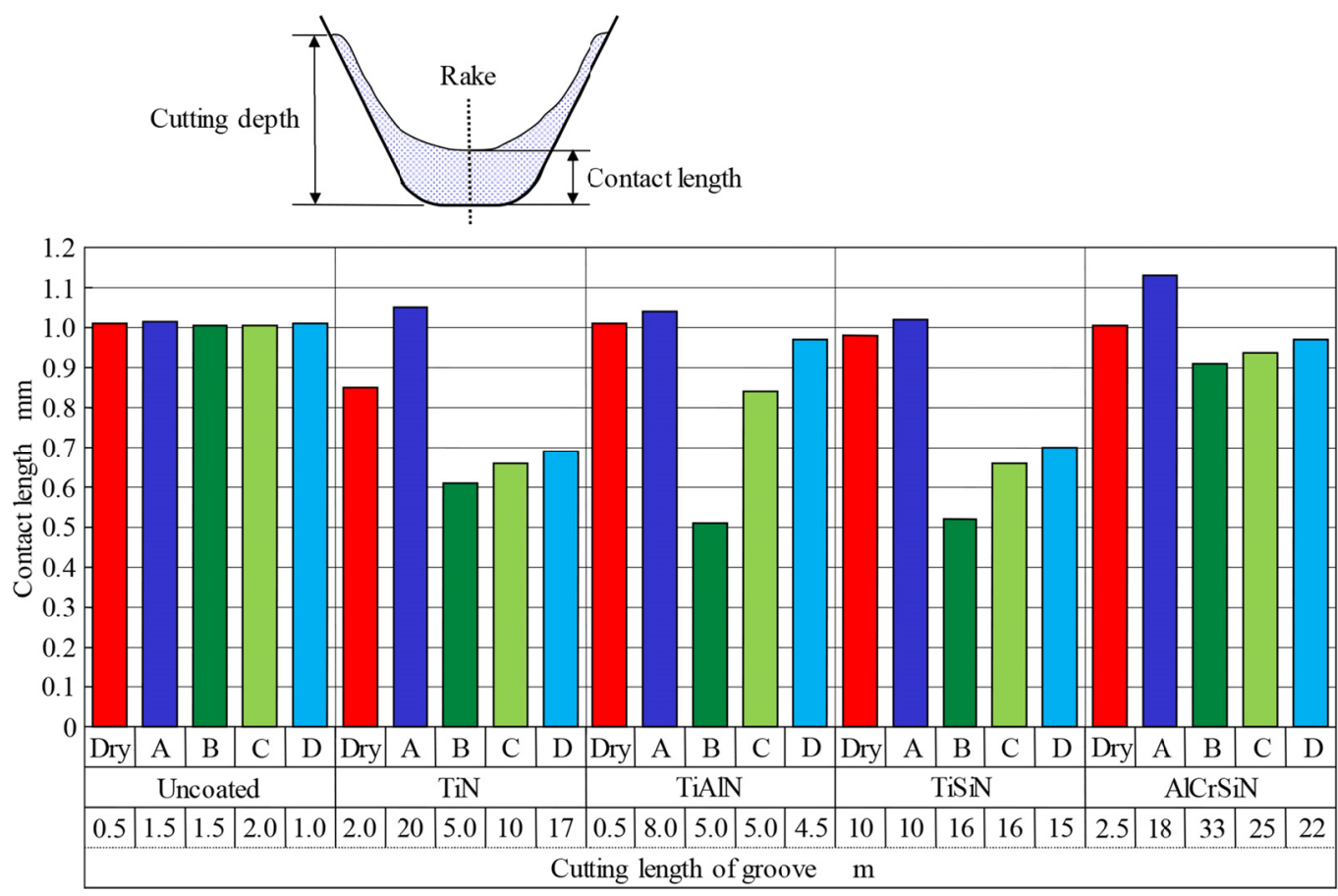

Figure 13. Contact length between the rake face and the chip (at the end of cutting)

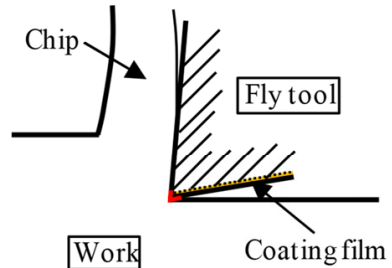

(a) Beginning of cut ting

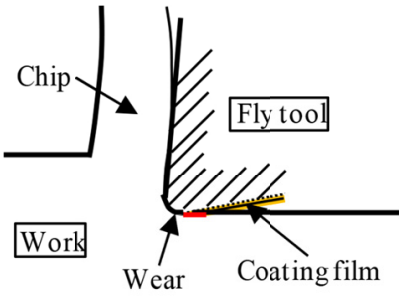

(b) End of cutting

Figure 14. Contact condition between the coating film and the work material

\subsection{Finshed Surface Roughness}

Figure 15 shows the finished surface roughness at the end of cutting for various coated tools and cutting fluids. The cutting groove length when the maximum flank wear width exceeded $0.3 \mathrm{~mm}$ differs depending on the cutting fluid and film coating. In the case of dry cutting, the finished surface roughness is approximately the same (3 to $4 \mu \mathrm{m})$ for the uncoated tool and the coated tools. In this experiment, the finished surface roughness on the side surface of the cut groove is measured in order to estimate the roughness of the gear tooth surface. The condition and wear of the tool side cutting edge are related to the finished surface roughness of the side surface. In the case of dry cutting, the deposited metal adheres from the rake face to the side cutting edge, as shown in Figure 16. Therefore, the finished surface roughness is considered to increase. Moreover, in the case of dry cutting, most of the coated tools reach their tool life during the initial stage of cutting, at which point side cutting edge wear has not appeared, and its influence on the finished surface roughness appears to be small.

In contrast, when using the cutting oil, the finished surface roughness decreased from one-half to one-quarter of that for dry cutting. In other words, when the cutting oil is used, the adhesion of deposited metal is observed on the rake face, but is hardly observed on the side cutting edges (see Figure 17), as in the case of dry cutting. The rake face that comes into contact with the chip is under high-temperature and high-pressure conditions compared with the flank face, and the temperature distribution is considered to be uneven. Thus, the adhesion amount also appears to be uneven because the deposited metal is dependent on the temperature. Therefore, adhesion of the deposited metal is assumed to have been prevented due to the anti-adhesion action of the cutting oil from observation of the side cutting edge. Because it is thought that the oil is more likely to penetrate at the side flank than at the center of the 
top flank (Shinozaki, 1958), which prevents the adhesion of the deposited metal. Based on the above considerations, the finished surface roughness obtained using the cutting oil is considered to be smaller than that obtained by dry cutting. In addition, when water-miscible cutting fluids are used, the finished surface roughnesses obtained using the TiSiN-and $\mathrm{AlCrSiN}$-coated tools are equal to or less than that obtained using the cutting oil and is approximately 1 $\mu \mathrm{m}$, despite the long cutting groove length. When using water-miscible cutting fluids, the finished surface roughness is considered to be small because almost no adhesion of the deposited metal is observed on the side cutting edge due to the anti-adhesion action, as in the case of using the cutting oil.

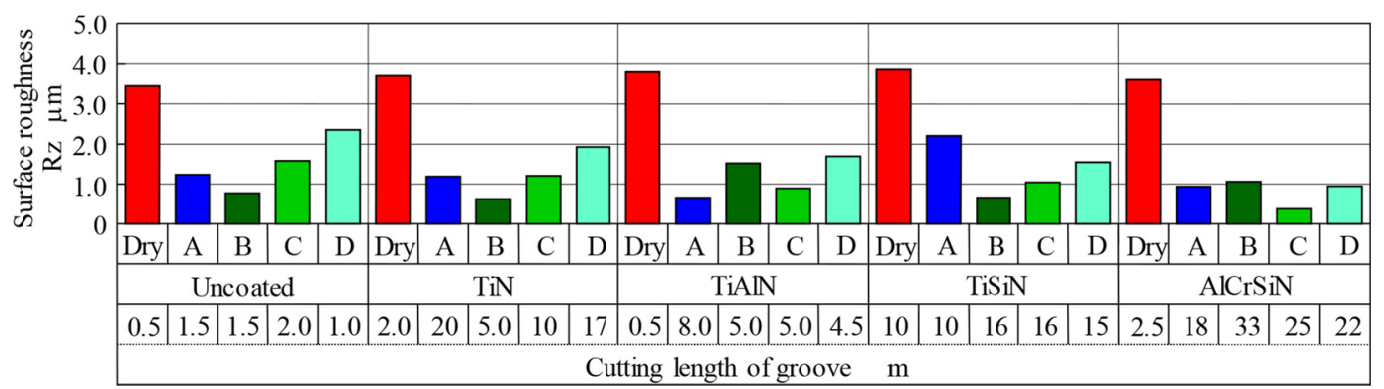

Figure 15. Surface roughness obtained using various coated tools (at the end of cutting)

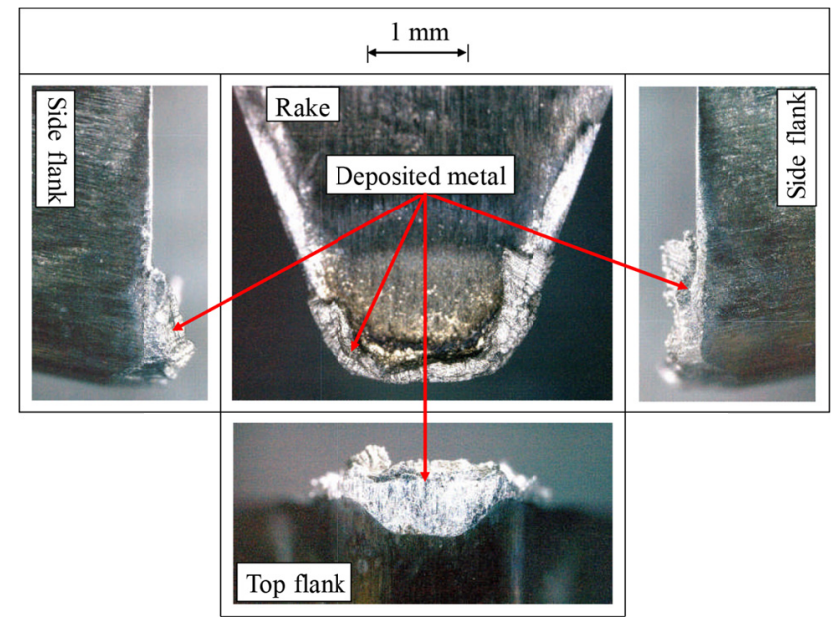

Figure 16. Metal deposited on the rake face, top flank and side flank (uncoated tool, dry cutting, cutting groove length: $0.5 \mathrm{~m}$ )

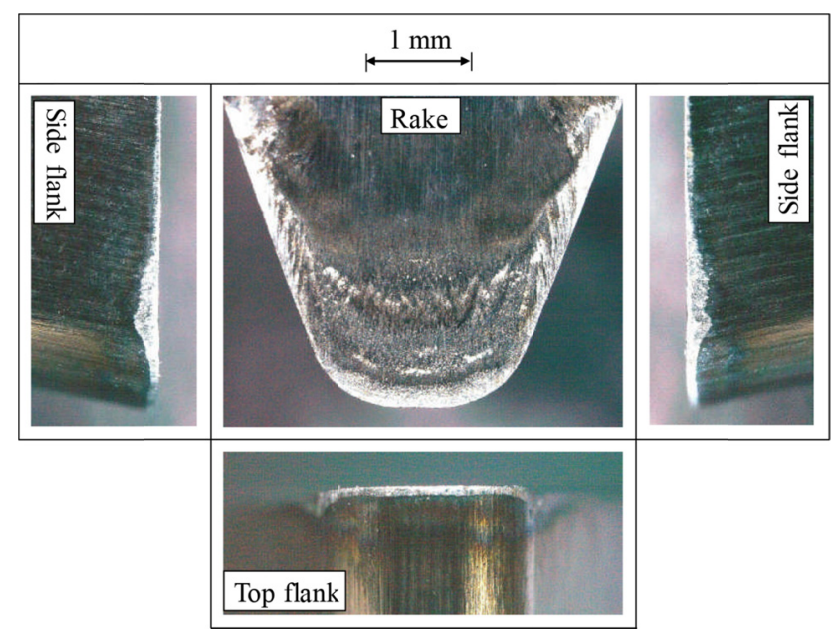

Figure 17. Condition of the rake face, top flank and side flank (uncoated tool, Oil A, cutting groove length: $1.5 \mathrm{~m}$ ) 
Figure 18 shows the finished surface roughness curves obtained for dry cutting and wet cutting using Oil $\mathrm{A}$ and Fluid $\mathrm{B}$ in conjunction with the $\mathrm{AlCrSiN}$-coated tool. In the case of dry cutting, at the beginning of cutting, a deep groove, such as a scratch resulting from the deposited metal, can be confirmed. When using Oil A, the cutter mark can be observed at almost the same interval as the feed rate $(0.99 \mathrm{~mm} / \mathrm{rev})$ and the roughness disturbance is also small. A glossy smooth surface was obtained, even when the finished surface was observed by microscope (see Figure 19). When using Fluid B, the surface roughness curves are smooth with a slight roughness disruption, although cutter marks cannot be confirmed. The difference in the finished surface roughness curves for dry cutting and wet cutting using Oil A and Fluid B is thought to be because the adhesion state of the deposited metal on the side cutting edge may be different. The finished surface roughness curves were thought to reflect transfer of the side cutting edge shape. In the case of using water-miscible cutting fluid, cutter marks did not appear due to fluctuation and/or vibration of the cutting tool because the lubricating performance is inferior to the case in which the cutting oil is used. When observed by microscope (see Figure 20), the finished surface is a glossy smooth surface. In the cases of dry cutting and wet cutting using Oil A and Fluid B, the finished surface roughness curve at the end of cutting is very similar to that at the beginning of cutting, and the values of the finishing surface roughness at both times are also very similar.

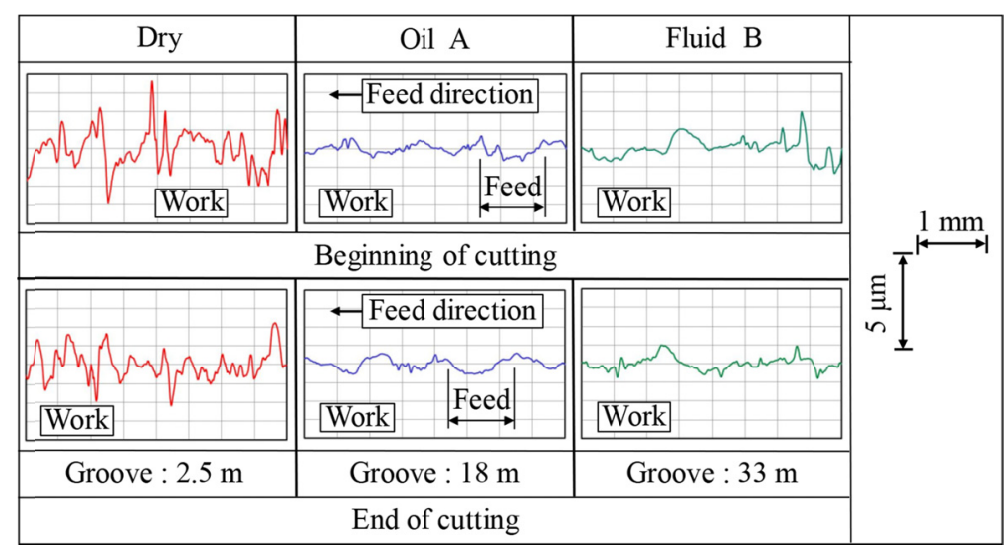

Figure 18. Finished surface roughness curves (AlCrSiN-coated tool, dry cutting and wet cutting using Oil A and Fluid B)

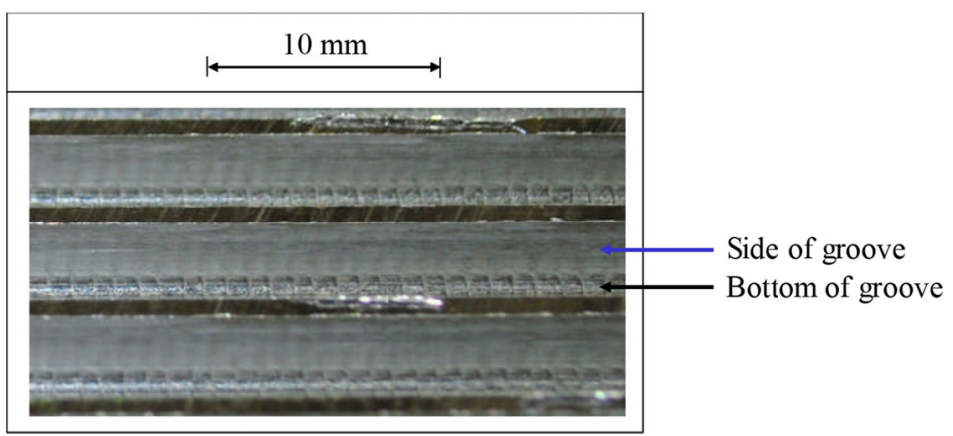

Figure 19. Condition of the finished surface (AlCrSiN-coated tool, Oil A)

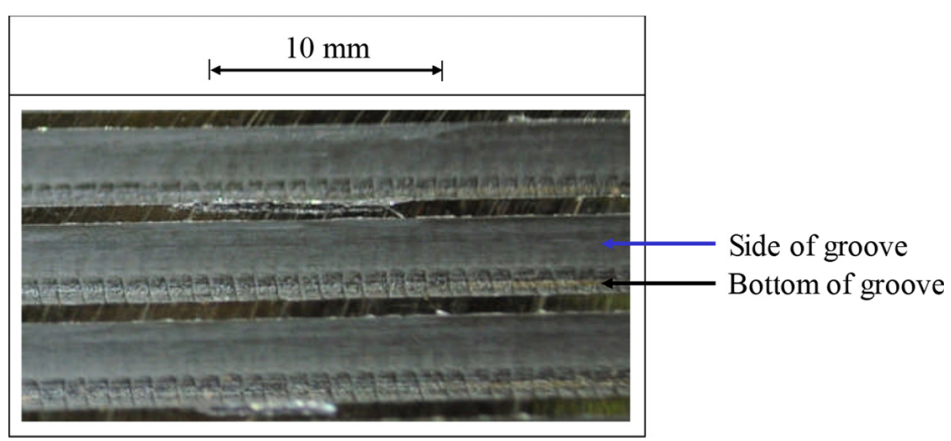

Figure 20. Condition of the finished surface (AlCrSiN-coated tool, Fluid B) 
This is considered to be due to the effect of the deposited metal on the finished surface roughness at the beginning of cutting, and the flank wear may be affected at the end of cutting.

In this experiment, there are notable differences in the adhesion amount of deposited metal on the side cutting edges and side cutting edge wear due to different cutting fluids and coated tools as factors influencing the finished surface roughness. In addition, the finished surface roughness is thought to be influenced by the fluctuation and vibration of the cutting tool singly or in combination. Regarding the difference in finished surface roughness due to differences in cutting fluids and coating films, the amount of deposited metal on the side cutting edge affects the finished surface roughness by observation of the cutting edge. When the adhesion amount of the deposited metal is large, the finished surface roughness tends to be large. The properties of the deposited metal generated are expected to differ based on the reactivity of the components contained in the cutting fluid, the coating film, and the work material, either singly or in combination. Therefore, more detailed analysis and observations will be necessary in the future.

\section{Conclusions}

In fly tool tests that simulated hobbing, the cutting performance of various water-miscible cutting fluids for various coated tools was investigated in comparison with dry cutting and water-immiscible cutting oil in terms of tool life (tool wear) and finished surface roughness. The main conclusions of the present study are summarized as follows:

1) Regarding flank wear, in the case of the uncoated tool, water-miscible cutting oil was more effective than dry cutting. For the TiN- and TiAlN-coated tools, water-immiscible cutting oil was effective. For TiSiNand $\mathrm{AlCrSiN}$-coated tools, using water-miscible cutting fluids prolonged tool life and was effective.

2) Regarding crater wear, in the case of the uncoated tool, water-immiscible cutting oil was effective. In the case of the TiN- and TiAlN-coated tools, water-immiscible and water-miscible cutting fluids were more effective than dry cutting. In the case of the TiSiN- and AlCrSiN-coated tools, water-miscible cutting fluid was effective and generated less crater wear.

3) Regarding finished surface roughness, in the case of dry cutting, the surface roughness was approximately the same for all of the coated tools. When water-immiscible cutting oil and water-miscible cutting fluids were used, the finished surface roughness was improved for all of the coated tools. When the water-miscible cutting fluids were used, the finished surface roughness was equal to or smaller than that obtained using the water-immiscible cutting oil.

4) From the viewpoints of flank wear, crater wear, and finished surface roughness, the emulsion-type water-miscible cutting fluid containing a large amount of synthetic lubricating additives was suitable for the AlCrSiN-coated tool.

\section{References}

Fujimura, Y. (1991). Machining methods for practical use. Kyoritsu Shuppan, 172.

Furuno, M. (2005). Development of roughing end mill coated AT for high-speed steels. Mechanical Engineering,53(9), 48-50.

Hida, A. (1985). On the corrosive wear. Junkatsu, 30(7), 467-471.

Katsuki, A., \& Matsuoka, H. (1991). Correspondence in tool wear between hobbing and cutting using a fly-tool. Report of the Faculty of Engineering, Oita University, (23), 7-13.

Kimura, K., \& Okabe, H. (1982). An introduction of tribology. Yokendo, 214-217.

Matsuoka, H., \& Tsuda, Y. (2010). Fundamental research on water-soluble cutting fluids for hobbing. Transactions of the Japan Society of Mechanical Engineers, Series C, 66(646), 2038-2048.

Matsuoka, H., Ono, H., \& Tsuda, Y. (2002). Fundamental research on water-soluble cutting fluids for hobbing $\left(1^{\text {st }}\right.$ Report, Comparison of performance with water-insoluble cutting oils). Transactions of the Japan Society of Mechanical Engineers, Series C, 68(671), 2188-2195.

Matsuoka, H., Ono, H., \& Tsuda, Y. (2006). Fundamental research on water-soluble cutting fluids for hobbing $\left(2^{\text {nd }}\right.$ Report, Cutting performance of various emulsions). Transactions of the Japan Society of Mechanical Engineers, Series C, 72(719), 2299-2307.

Matsuoka, H., Ono, H., \& Tsuda, Y. (2009). Fundamental research on water-soluble cutting fluids for hobbing ( ${ }^{\text {rd }}$ Report, Effect of pH). Transactions of the Japan Society of Mechanical Engineers, Series C, 75(756), 2200-2209.

Nakayama, K. (1978). The metal cutting in its principle. Corona Publishing, 159. 
Ohgo, K., Nakajima, K., \& Awano, T. (1976). A study of peeling mode of a built-up edge from the rake face and the wear of a cutting tool during machining -Effect of cutting fluid-. Journal of Japan Society of Lubrication Engineers, 21(7), 447-451.

Okabe, H. (1973). Wear in corrosive environments. Junkatsu, 18(4), 335-336.

Rech, J. (2006). Influence of cutting edge preparation on the wear resistance in high speed dry gear hobbing. Wear, 261(5-6), 505-512.

Sakurai, M., \& Terao H. (2007). New generation AIP coating film for cutting tools. Machine and Tool, 21-25.

Shinozaki, N., \& Yoshikawa, H. (1958). The lubricating effect of cutting fluids (1st Report). Journal of the Japan Society of Precision Engineering, 24(3), 140-145.

Takeyama, H. (1982a). Cutting process. Maruzen, 78.

Takeyama, H. (1982b). Cutting process. Maruzen, 76.

Takeyama, H. (1982c). Cutting process. Maruzen, 31.

Terashima, K., \& Ueno, T. (1977). Numerical analysis of cutting conditions of space of hob tooth. Transactions of the Japan Society of Mechanical Engineers, 43(373), 3535-3547.

Usui, E., \& Mizuhara, K. (1980). On the action of cutting fluids -Mechanical aspects-. Journal of Japan Society of Lubrication Engineers, 21(7), 136-144.

Wakuri, A., Ueno, T., Ainoura, M., \& Katsuki, A. (1972). Fundamental research on hobbing hard gears using fly-Tools. Bulletin of the JSME, 15(87), 1130-1142.

Weinert, K., Inasaki, I., Sutherland, J.W., \& Wakabayashi, T. (2004). Dry machining and minimum quantity lubrication. Annals of the CIRP, 53(2), 511-537.

\section{Copyrights}

Copyright for this article is retained by the author(s), with first publication rights granted to the journal.

This is an open-access article distributed under the terms and conditions of the Creative Commons Attribution license (http://creativecommons.org/licenses/by/4.0/). 